\title{
REFORMATTING STATISTICAL EDUCATION IN RUSSIA: CHANGES IN CLASSIFICATIONS, STANDARDS, AND PROGRAMS
}

\author{
Alexey Ponomarenko \\ Higher School of Economics, Russian Association of Statisticians, Russia \\ ponomarenko26212@gmail.com
}

In the centrally planned economy the main function of official statistics was monitoring of plans' execution. Hence, official statisticians had to be experts in economics and bookkeeping, like tax inspectors. Russian statistical education was oriented mostly to official needs and statistics was included in the same educational group as economics. Currently, professional requirements for statisticians have changed. Official statistics lost its control function, and the old reporting system is being replaced by sample surveys that are less onerous for respondents and also less expensive. The statistical agency needs more professionals in survey methodology, as well as statistical managers and mathematicians. In 2015, the new professional standard "statistician" was accepted in Russia in line with ISCO 2008. It consists of set of competences for professionals in data collection, processing, analysis and methodology in any field of activity, including business, finance, science, medicine. In 2016, the educational classification of statistics was changed to the same group as mathematics. A new educational standard for statistics was also accepted. This presentation describes part of the reconstructive process. 